\title{
TEORES DE ZINCO, COBRE, MANGANÊS E FERRO EM DOIS LATOSSOLOS SOB PLANTIOS DIRETO E CONVENCIONAL $\left({ }^{1}\right)$
}

\author{
ORLANDO MELO DE CASTRO $\left({ }^{2.5}\right)$, OTÁVIO ANTONIO DE CAMARGO $\left({ }^{3,5}\right)$, \\ HETTOR CANTARELLA $\left({ }^{4,5}\right)$, SIDNEY ROSA VIEIRA $\left({ }^{2,5}\right)$ \\ e SONIA CARMELA FALCI DECHEN $\left({ }^{2}\right)$
}

\begin{abstract}
RESUMO
Estudou-se a influência dos sistemas de plantio direto e preparo convencional, após três anos de cultivo, nos teores de zinco, cobre, manganês e ferro, extraídos com DTPA-TEA, em dois latossolos vermelho-amarelos (LV) do Estado de Sāo Paulo: um de textura argilosa, em Itatiba, e outro de textura média, em Casa Branca. Utilizaram-se amostras coletadas em cinco camadas (0-5, 5-10, 10-20, 20-30 e $30-50 \mathrm{~cm}$ ), com doze pontos de amostragem por tratamento. Observou-se, em profundidade, um decréscimo acentuado nos níveis de zinco e de manganes nos dois latossolos, e de ferro no LV textura argilosa, podendo a diminuição dos teores de matéria orgânica ser um dos fatores responsáveis por esse decréscimo, principalmente para $\mathrm{Zn}$ e $\mathrm{Mn}$. Houve diferenças significativas nos níveis de cobre e de manganês nos dois sistemas de preparo do solo no LV textura argilosa, sendo os teores de cobre e de manganês maiores no plantio direto. O sistema de cultivo năo influiu nos teores de zinco e de ferro nos doís latossolos.
\end{abstract}

Termos de indexação: micronutrientes no solo, plantio direto, manejo do solo.

\section{ABSTRACT \\ ZINC, COPPER, MANGANESE, AND IRON CONTENT IN TWO LATOSOLS FROM SĀO PAULO STATE, BRAZIL, UNDER CONVENTIONAL AND NO-TILLAGE CROPPING SYSTEM}

\begin{abstract}
The effect of three years cropping (1982 to 1985) under no-tillage and conventional tillage on the DTPA-TEA extractable zinc, copper, manganese, and iron content of a clayey and a medium-textured Red-Yellow Latosols from São Paulo State, Brazil, were studied. The sites were sampled at five depths $(0-5 \mathrm{~cm}, 5-10 \mathrm{~cm}, 10-20 \mathrm{~cm}, 20-30 \mathrm{~cm}$, and $30-50 \mathrm{~cm})$ with twelve replications per treatment. Increasing the depth, a significant decrease in the levels of zinc and manganese, in both soils, and of iron in the clayey Red Yelow-Latosol, was observed. Variations in the concentration of zinc, manganese, and iron were highly correlated with the soil organic matter content. The levels of copper and manganese were affected by the tillage system in the clayey Red-Yellow Latosol: both elements were higher in the no-tillage treatment. On the other hand, the tillage system did not affect the concentration of zinc and iron in the soils studied.
\end{abstract}

Index terms: soil micronutrients, no-tillage, soil management.

( $\left.{ }^{1}\right)$ Recebido para publicação em 2 de janeiro e aceito em 3 de julho de 1992.

$\left({ }^{2}\right)$ Seção de Conservação do Solo, Instituto Agronômico (IAC), Caixa Postal 28, 13001-970 Campinas (SP).

$\left.{ }^{3}\right)$ Seçāo de Pedologia, IAC.

$\left({ }^{4}\right)$ Seçāo de Fertilidade do Solo e Nutrição de Plantas, IAC.

(5) Bolsista do CNPq. 


\section{INTRODUÇÃO}

Os solos são cultivados não só para assegurar um ótimo crescimento das plantas, mas, também, para proporcionar boas condições para outras práticas agrícolas, como semeadura e colheita. Entretanto, nem sempre se tem garantido que operaçōes de cultivo sejam vantajosas ou praticáveis em todas as circunstâncias. A erosão excessiva, o tempo de trabalho e o alto custo energético levam, muitas vezes, - agricultor a procurar opções aos sistemas de cultivos convencionais. $O$ plantio direto apresenta-se como alternativa e vem sendo adotado por agricultores paulistas.

Pesquisas realizadas em diversas regiōes têm mostrado alteraçōes significativas em propriedades químicas de solo sob plantio direto, quando comparado com cultivo convencional (Phillips \& Young Jr., 1973; Blevins et al., 1983a; Castro et al., 1987). A maior parte dos estudos indica que o plantio direto, entre outros efeitos, provoca um aumento no teor de matéria orgânica e diminuição do $\mathrm{pH}$ do solo na camada superficial em relação ao plantio convencional (Shear \& Moschler, 1969; Blevins et al., 1977, 1983b; Follet \& Peterson, 1988). Essas modificações podem provocar alteraçōes na disponibilidade de micronutrientes no solo. Mahler et al. (1982), no Estado de Idaho (EUA), encontraram diferenças significativas no teor e na distribuição de $\mathrm{Zn}, \mathrm{Cu}$, Fe e Mn em molissolo. Blevins et al. $(1977,1983 b)$ observaram que os teores de Mn trocável eram maiores em área sob plantio direto que naquela arada e gradeada; os valores mais elevados de $\mathrm{Mn}$ coincidiram com os de $\mathrm{pH}$ mais baixos. Resultados semelhantes foram observados por Follet \& Peterson (1988) para $\mathrm{Zn}, \mathrm{Cu}, \mathrm{Pb}, \mathrm{Fe}$, Mn e Cd extraídos com DTPA. Em área de solo mais intemperizado do Sudeste americano, Hargrove et al. (1982) atribuíram o acúmulo de $\mathrm{Mn}$ e $\mathrm{Zn}$ na superfície de um solo, sob o plantio direto, ao acúmulo de resíduos de plantas. Esses autores não observaram diferenças significativas em relação ao $\mathrm{Cu}$ nas áreas sob plantio direto e convencional.

Faltam informações sobre o assunto para os solos brasileiros. Portanto, o objetivo do presente estudo foi verificar a alteração dos teores e a distribuição de $\mathrm{Cu}, \mathrm{Zn}, \mathrm{Mn}$ e $\mathrm{Fe}$ em latossolos submetidos a plantio direto e convencional por três anos.

\section{MATERIAL E METODOS}

O experimento foi desenvolvido em um latossolo vermelho-amarelo textura argilosa (LV-1) e em um latossolo vermelho-amarelo textura média (LV-2), localizados, respectivamente, nos municípios paulistas de Itatiba e Casa Branca, cujas principais características se encontram no quadro 1 . Segundo a classificação de Köppen, a região de Itatiba apresenta clima subtropical úmido sem estação seca no inverno, e a de Casa Branca, clima subtropical úmido, com inverno seco.

Os latossolos estavam sob preparo convencional havia muitos anos, sendo que, no ano anterior ao início do experimento (1981), fez-se uma calagem com $3 \mathrm{t}$ /ha de calcário dolomítico, incorporadas com arado de discos. Fez-se, também, uma escarificaçāo geral para eliminar camadas compactadas. As áreas assim preparadas foram divididas em duas faixas adjacentes de $3.000 \mathrm{~m}^{2}(20 \times 150 \mathrm{~m})$ cada uma, ficando uma sob plantio direto e a outra, sob preparo convencional (uma aração + duas gradagens) com a seguinte sucessão de culturas: soja/trigo no LV-2, e soja/trigo-milho/trigo no LV-1, estando o trigo, neste solo, sob irrigação. Durante os três anos do experimento, as áreas foram trabalhadas com máquinas de preparo (apenas aquelas sob manejo convencional), plantio e colheita normalmente empregadas na propriedade agrícola. A adubação utilizada, por hectare, nas culturas, foi a seguinte: para o trigo, $20 \mathrm{~kg}$ de $\mathrm{N}, 80 \mathrm{~kg}$ de $\mathrm{P}_{2} \mathrm{O}_{5}$ e $50 \mathrm{~kg}$ de $\mathrm{K}_{2} \mathrm{O}$ no plantio e $40 \mathrm{~kg}$ de $\mathrm{N}$ em cobertura; para a soja, $40 \mathrm{~kg}$ de $\mathrm{P}_{2} \mathrm{O}_{5}$ e $50 \mathrm{~kg}$ de $\mathrm{K}_{2} \mathrm{O}$ no plantio e, para o milho, $5 \mathrm{~kg}$ de $\mathrm{N}, 60 \mathrm{~kg}$ de $\mathrm{P}_{2} \mathrm{O}_{5}$ e $30 \mathrm{~kg}$ de $\mathrm{K}_{2} \mathrm{O}$ no plantio e $90 \mathrm{~kg}$ de $\mathrm{N}$ em cobertura.

Efetuaram-se as amostragens do solo ao final do terceiro ano de cultivo (julho de 1985), com doze pontos de amostragem por faixa, seguindo o sentido do comprimento: cada repetição era composta de cinco subamostras, retiradas nas profundidades de 0-5, 5-10, 10-20, 20-30 e 30-50 cm. Os elementos $\mathrm{Zn}$, $\mathrm{Cu}, \mathrm{Fe}$ e Mn foram extraídos com solução de DTPA-TEA em pH 7,3 e analisados por espectrofotometria de absorção atômica, conforme método descrito por Camargo et al. (1986). Analisaram-se os resultados estatisticamente, aplicando-se o teste t. Calcularam-se também as correlações dos teores de micronutrientes com o $\mathrm{pH}$ e o teor de matéria orgânica do solo, dentro de cada sistema de preparo. 
Quadro 1. Principais atributos do latossolo vermelho-amarelo textura argilosa (LV-1) e do latossolo vermelho-amarelo textura média (LV-2) sob plantio direto (PD) e convencional (PC), após três anos de cultivo

\begin{tabular}{|c|c|c|c|c|c|}
\hline Solo/Tratamento & Profundidade & Argila & $\begin{array}{l}\text { Matéria } \\
\text { orgânica }\end{array}$ & $\mathrm{pH} \mathrm{H}_{2} \mathrm{O}$ & $\begin{array}{l}\text { Soma } \\
\text { de bases }\end{array}$ \\
\hline & $\mathbf{c m}$ & 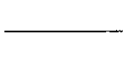 & 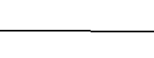 & & $\mathrm{meq} / 100 \mathrm{~g}$ \\
\hline \multirow[t]{5}{*}{ LV-1 PD } & $0-5$ & 59 & 4,3 & 5,9 & 4,1 \\
\hline & $5-10$ & 59 & 3,6 & 5,9 & 3,5 \\
\hline & $10-20$ & 59 & 3,1 & 5,5 & 2,9 \\
\hline & $20-30$ & 60 & 2,2 & 5,0 & 0,9 \\
\hline & $30-50$ & 60 & 2,1 & 5,0 & 1,5 \\
\hline \multirow[t]{5}{*}{ LV-1 PC } & $0-5$ & 56 & 4,1 & 6,0 & 4,8 \\
\hline & $5-10$ & 60 & 3,9 & 5,9 & 4,7 \\
\hline & $10-20$ & 62 & 3,6 & 5,4 & 2,5 \\
\hline & $20-30$ & 62 & 2,6 & 5,0 & 1,6 \\
\hline & $30-50$ & 65 & 2,0 & 5,0 & 1,5 \\
\hline \multirow[t]{5}{*}{ LV-2 PD } & $0-5$ & 25 & 1,5 & 6,0 & 3,4 \\
\hline & $5-10$ & 26 & 1,4 & 6,2 & 3,0 \\
\hline & $10-20$ & 25 & 1,4 & 6,3 & 3,1 \\
\hline & $20-30$ & 29 & 1,0 & 6,0 & 2,4 \\
\hline & $30-50$ & 29 & 1,0 & 5,0 & 1,5 \\
\hline \multirow[t]{5}{*}{ LV-2 PC } & $0-5$ & 27 & 1,7 & 6,5 & 3,0 \\
\hline & $5-10$ & 27 & 1,4 & 6,4 & 3,0 \\
\hline & $10-20$ & 27 & 1,2 & 6,3 & 2,4 \\
\hline & $20-30$ & 27 & 1,2 & 5,8 & 1,7 \\
\hline & $30-50$ & 29 & 1,2 & 5,0 & 0,8 \\
\hline
\end{tabular}

\section{RESULTADOS E DISCUSSÃO}

Nas amostras estudadas, como se pode observar nas figuras 1 e 2 , os valores de zinco encontrados variaram de 1,1 ppm para o LV-1 em plantio convencional até 4,2 ppm para o $\mathrm{LV}-2$, ambos nas camadas superficiais. $O$ teor de zinco, em todas as condiçōes do estudo, decresceu sensivelmente em profundidade. Valadares (1972) encontrou valores mais baixos que estes, em torno de $0,9 \mathrm{ppm}$ de zinco para a camada superficial de latossolo vermelho-amarelo textura argilosa e $0,1 \mathrm{ppm}$ para o horizonte B-22. Para o latossolo vermelho-amarelo de textura média, encontrou $0,1 \mathrm{ppm}$ para todos os horizontes. Para os dois solos e tratamentos, houve correlação linear apenas entre o teor de zinco e a porcentagem de matéria orgânica, com coeficientes de determinação $\left(r^{2}\right)$, para o plantio direto, de 0,75 e 0,72 para o LV-1 e LV-2 respectivamente; os valores correspondentes para o plantio convencional foram 0,54 e 0,55 (Quadro 2). Alta correlação, entre o teor de Zn extraído por DTPA e a matéria orgânica também foi observada por Follet \& Peterson (1988). Esses autores, bem como Hargrove et al. (1982), notaram que os teores de $\mathrm{Zn}$ disponivel eram maiores no plantio direto que no convencional; no entanto, as diferenças ficaram restritas à camada superficial. No presente estudo, não houve, nos dois solos, diferença no teor de $\mathrm{Zn}$ em nenhuma profundidade, para ambos os sistemas de cultivo (Figuras 1 e 2).

Lopes (1983), em solos sob cerrado, encontrou concentrações de cobre solúvel em $\mathrm{HCl} 0,05 \mathrm{~N}+$ $\mathrm{H}_{2} \mathrm{SO}_{4} 0,025 \mathrm{~N}$ que variaram de traços a $9,7 \mathrm{ppm}$. No presente trabalho, os teores, extraídos por DTPA-TEA, foram de 0,6 ppm para a camada superficial 
do LV-1, no plantio direto, até $0,2 \mathrm{ppm}$ no LV-2, no convencional. A distribuição do cobre ao longo dos perfis dos solos foi um pouco diferente da do zinco (Figuras 1 e 2): a amplitude de variaçāo dos teores foi baixa e estes nāo diminuíram em profundidade como o zinco, náo apresentando também correlação com o conteúdo de matéria orgânica.

Ambos os solos mostraram teores de cobre significativamente mais elevados sob o plantio direto que sob o tradicional, especialmente nas camadas superficiais, embora as diferenças de concentração do elemento devido ao manejo do solo não tenham atingido $0,2 \mathrm{ppm}$. No solo de textura argilosa, o teor de $\mathrm{Cu}$ mostrou-se mais elevado sob o plantio direto também na camada de $20-50 \mathrm{~cm}$ de profundidade, não se tendo uma explicação para o fato.
No presente trabalho, o teor máximo de manganês encontrado foi de $8,8 \mathrm{ppm}$ na camada de 0-5 cm do latossolo vermelho-amarelo textura argilosa no plantio direto e o mínimo de $0,2 \mathrm{ppm}$ na camada de $20-30 \mathrm{~cm}$ do mesmo solo. Valadares \& Camargo (1983) encontraram valores de $\mathbf{M n}$ extraído com DTPA na camada arável de um latossolo vermelho-amarelo de Atibaia igual a 9,8 ppm e, para um latossolo vermelho-amarelo textura média de Casa Branca igual a 1,9 ppm, valores esses semelhantes aos obtidos no presente estudo. Em todos os casos, o teor de Mn extraído com DTPA diminuiu sensivelmente com a profundidade (Figuras 1 e 2), havendo boa correlação entre essa variável e a porcentagem de matéria orgânica no solo, possível fator responsável pela distribuição do elemento no perfil (Quadro 2). Resultados semelhantes foram observados por Follet \& Peterson (1988).

Quadro 2. Valores dos coeficientes a e b e de $\mathbf{r}^{2}$ da regressão linear entre os teores de micronutrientes e matéria orgânica nos solos LV-1 e LV-2, em plantio direto (PD) e convencional (PC)

\begin{tabular}{|c|c|c|c|c|c|}
\hline \multirow{2}{*}{ Elemento } & \multirow{2}{*}{\multicolumn{2}{|c|}{ Solo/Tratamento }} & \multicolumn{2}{|c|}{ Parâmetros da regressão } & \multirow{2}{*}{$r^{2}\left({ }^{1}\right)$} \\
\hline & & & $\mathbf{a}$ & b & \\
\hline \multirow[t]{4}{*}{ Zinco } & LV-1 & PD & $-0,73$ & 0,73 & $0,75^{* *}$ \\
\hline & & PC & $-0,46$ & 0,56 & $0,54^{*}$ \\
\hline & LV-2 & PD & $-4,30$ & 8,08 & $0,72^{* *}$ \\
\hline & & PC & $-2,72$ & 5,43 & $0,55^{*}$ \\
\hline \multirow[t]{4}{*}{ Cobre } & LV-1 & PD & 0,57 & 2,31 & $0,31 \mathrm{~ns}$ \\
\hline & & PC & 1,56 & 0,51 & $0,07 \mathrm{~ns}$ \\
\hline & LV-2 & PD & $-0,71$ & 0,11 & $0,01 \mathrm{~ns}$ \\
\hline & & PC & 0,87 & $-0,18$ & $0,02 \mathrm{~ns}$ \\
\hline \multirow[t]{4}{*}{ Manganês } & LV-1 & PD & $-5,14$ & 4,95 & $0,72 * *$ \\
\hline & & PC & $-6,57$ & 6,44 & $0,61^{*}$ \\
\hline & LV-2 & PD & $-1,36$ & 3,90 & $0,82 * *$ \\
\hline & & PC & $-2,37$ & 4,54 & $0,66^{*}$ \\
\hline \multirow[t]{4}{*}{ Ferro } & LV-1 & PD & $-6,72$ & 23,47 & $0,56^{*}$ \\
\hline & & PC & $-13,43$ & 29,14 & $0,63^{*}$ \\
\hline & LV-2 & PD & 0,78 & $-0,02$ & $0,01 \mathrm{~ns}$ \\
\hline & & PC & 0,89 & $-0,01$ & $0,01 \mathrm{~ns}$ \\
\hline
\end{tabular}

$\left({ }^{1}\right) e^{* *}=$ coeficientes de correlação significativos a 1 e $5 \%$ respectivamente; ns = não significativo. 

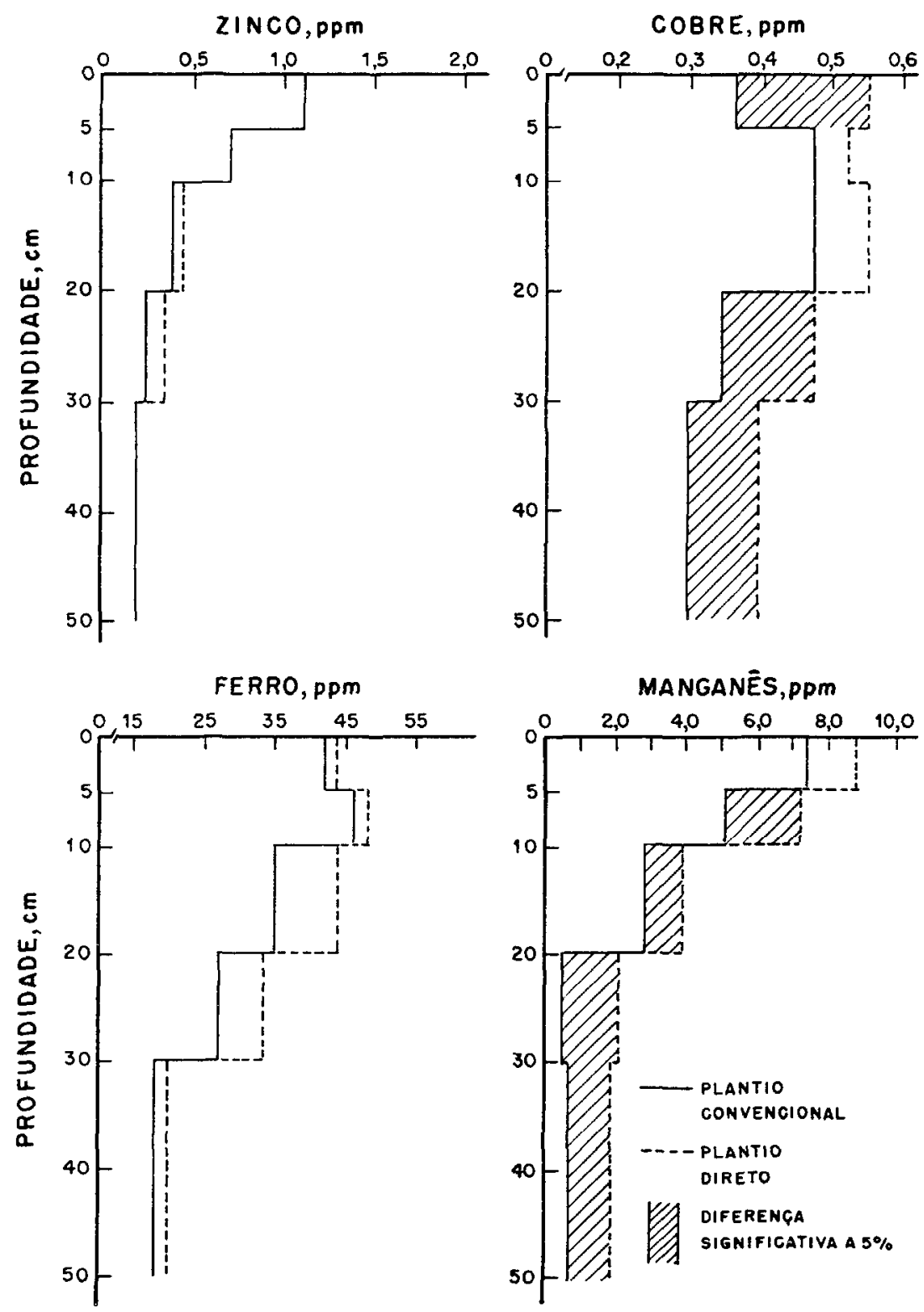

Figura 1. Teores médios de zinco, cobre, ferro e manganês extraídos com EDTA-TEA, em um latossolo vermelho-amarelo de textura argilosa, submetido a três anos de plantio direto ou convencional.

O teor de manganês foi significativamente maior nas camadas abaixo de $5 \mathrm{~cm}$, nas amostras de $\mathrm{LV}-1$ sob o plantio direto. Na camada superficial $(0-5 \mathrm{~cm})$, a diferença não atingiu significância estatística devido, provavelmente, à maior variabilidade dos resultados. Como o LV-1 é um solo com teor de matéria orgânica maior que o LV-2 (Castro et al.,
1987) e de manganês total também maior (Valadares \& Camargo, 1983), alteraçōes no manejo deste solo têm mais chances de ocasionar diferenças significativas no teor do elemento. $\mathrm{O}$ maior teor de $\mathrm{Mn}$ neste solo sob plantio direto pode estar relacionado à maior preservação da umidade, em vista do sistema de cultivo. 

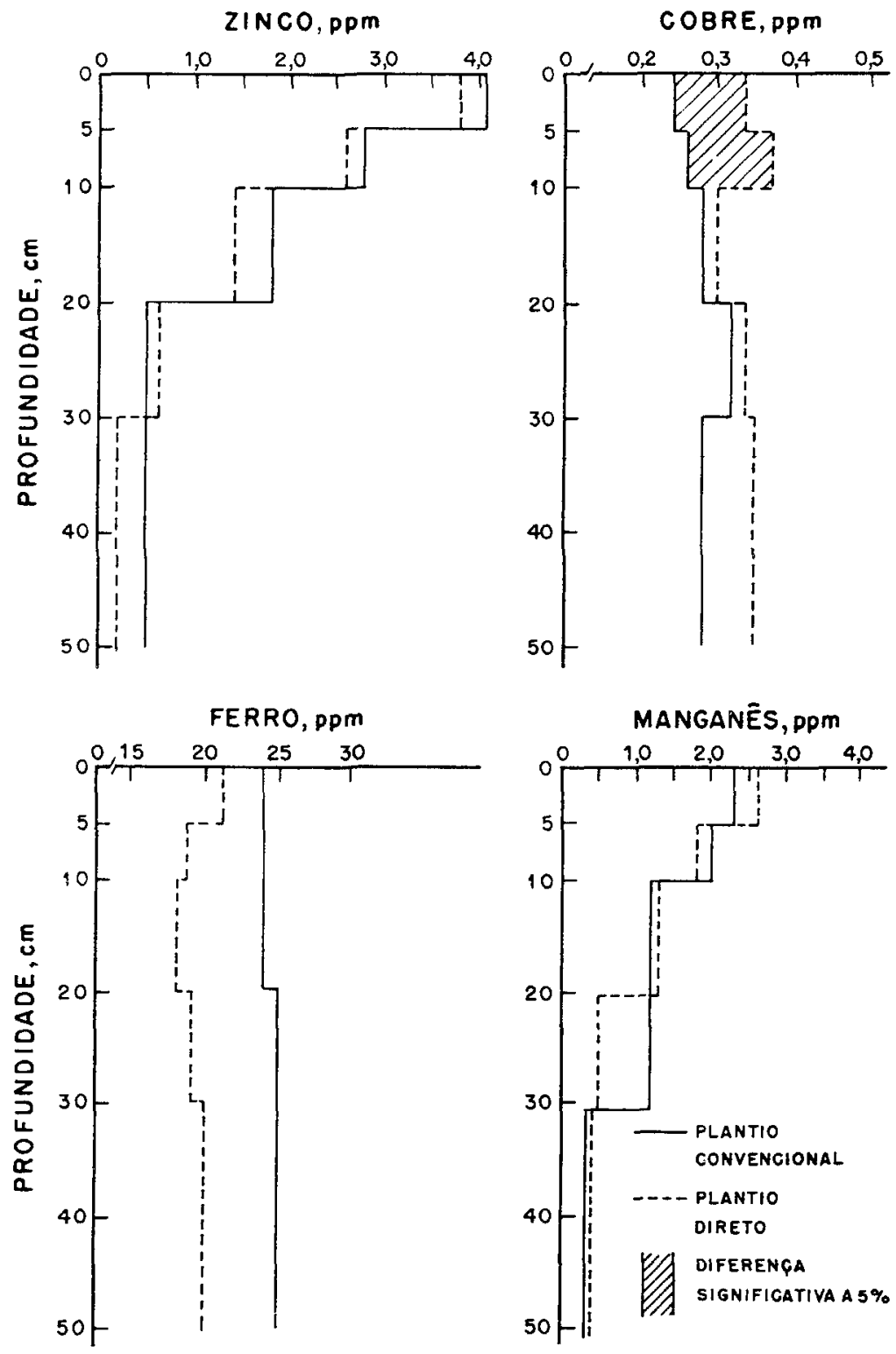

Figura 2. Teores médios de zinco, cobre, ferro e manganês extraídos com EDTA-TEA, em um latossolo vermelho-amarelo de textura média, submetido a três anos de plantio direto ou convencional.

Os resultados encontrados para o Mn coincidem com aqueles de diversos autores, que também observaram maiores teores de Mn nas áreas sob plantio direto (Blevins et al., 1977, 1983b; Hargrove et al., 1982; Follet \& Peterson, 1988).

Quanto ao ferro, os teores do elemento variaram de 48 ppm na camada de $5-10 \mathrm{~cm}$ do LV-1 a 18 ppm na de 30-50 cm no mesmo solo. No LV-2, variou muito pouco com a profundidade, situando-se de uma média de $25 \mathrm{ppm}$ na camada de $0-5 \mathrm{~cm}$ a $20 \mathrm{ppm}$ na de 10-20 cm (Figuras 1 e 2). Esses valores estão abaixo dos obtidos por Camargo et al.(1982), que determinaram teores de Fe, extraído com DTPA, de $36 \mathrm{ppm}$, para um latossolo vermelho-amarelo textura arenosa, e de $75,8 \mathrm{ppm}$ para um textura argilosa húmico. Observou-se que houve correlação do teor de ferro com a porcentagem de matéria orgânica no LV-1 (Quadro 2), evidenciando que esse componente deve ser primordial no controle da disponibilidade do ferro neste solo. Nenhuma diferença significativa foi notada nos teores do elemento entre as duas condiçōes estudadas para cada solo. 
De modo geral, as variações provocadas pelos sistemas de manejo sobre os teores de micronutrientes extraídos por DTPA foram modestas, mesmo quando atingiram significância estatística, não sendo suficientes, provavelmente, para afetar significativamente a disponibilidade desses elementos para as plantas. É provável que o motivo sejam as alterações relativamente pequenas que ocorreram nos solos em função dos três anos de aplicação dos sistemas de preparo: houve aumentos nos teores de $P$ e $K$ e na agregação e retençāo de água nas camadas superficiais do LV de textura argilosa e aumento de $\mathrm{P}$ e $\mathrm{Mg}$ e redução do $\mathrm{pH}$ nos solos de textura média submetidos ao plantio direto (Castro et al., 1987). No entanto, ao contrário dos resultados de Blevins et al. (1977, 1983b), não ocorreu acúmulo significativo de matéria orgânica nos solos sob plantio direto, provavelmente pelo curto período (três anos) de aplicação dos tratamentos e pelas condições climáticas que favorecem uma rápida decomposição dos restos de cultura na superfície do solo. Hargrove et al. (1982), após quatro anos de plantio direto no Sul dos EUA, também não observaram aumentos no teor de matéria orgânica, como acontece em áreas de clima temperado; notaram, porém, um acúmulo de $\mathrm{Zn}$ e de $\mathrm{Mn}$, mas não de $\mathrm{Cu}$, na camada superficial. Shuman \& Hargrove (1985), analisando amostras da camada de 0-2 cm de solo submetido por oito anos ao plantio direto e ao convencional, não encontraram praticamente diferença nos teores de $\mathrm{Zn}, \mathrm{Mn}, \mathrm{Cu}$ e Fe extraídos com o extrator de Mehlich, mas observaram que, no plantio direto, houve uma diminuição nos teores de $\mathrm{Fe}$ e Mn ligados à fração óxido de ferro e um aumento daqueles elementos na fração orgânica; o fracionamento do $\mathrm{Cu}$ e do $\mathrm{Zn}$ mostrou pouco efeito dos sistemas de preparo.

\section{CONCLUSŌES}

1. O sistema de plantio direto no latossolo textura argilosa provocou um aumento nos teores de cobre e manganês no solo. No de textura média, só ocorreu aumento de cobre na camada de 0-10 cm.

2. A distribuição de zinco e manganês nos dois solos e de ferro no latossolo de textura argilosa apresentou boa correlação com o teor de matéria orgânica.

\section{AGRADECIMENTOS}

Os autores agradecem aos proprietários e ao corpo técnico das fazendas Baronesa, em Itatiba, e Cocais do Rio Verde, em Casa Branca, o apoio recebido na realização do experimento.

\section{REFERENCIAS BIBLIOGRÁFICAS}

BLEVINS, R.L.; SMITH, M.S.; THOMAS, G.W. \& FRYE, W.W. Influence of conservation tillage on soil properties. Journal of Soil \& Water Conservation, Ankeny, 38(3):301-305, $1983 \mathrm{a}$.

BLEVINS, R.L.; THOMAS, G.W. \& CORNELIUS, P.L. Influence of no-tillage and nitrogen fertilization on certain soil properties after 5 years of continuous corn. Agronomy Journal, Madison, 69(3):383-386, 1977.

BLEVINS, R.L.; THOMAS, G.W.; SMITH, M.S.; FRYE, W.W. \& CORNELIUS, P.L. Changes in soil properties after 10 years continuous non-tilled and conventionally tilled corn. Soil \& Tillage Research, Amsterdam, 3(2):135-146, $1983 \mathrm{~b}$.

CAMARGO, O.A. de; MONIZ, A.C.; JORGE, J.A. \& VALADARES, J.M.A. da S. Métodos de análise química, mineralógica e fisica de solos do Instituto Agronômico de Campinas. Campinas, Instituto Agronómico, 1986. 94p. (Boletim técnico, 106)

CAMARGO, O.A. de; VALADARES, J.M.A. da S. \& DECHEN, A.R. Efeitos do pH e da incubação na extração do manganês, zinco, cobre e ferro do solo. Revista Brasileira de Ciência do Solo, Campinas, 6(2):83-88, 1982.

CASTRO, O.M. de; CAMARGO, O.A. de; VIEIRA, S.R.; DECHEN, S.C.F. \& CANTARELLA, H. Caracterização química e fisica de dois latossolos em plantio direto e convencional. Campinas, Instituto Agronómico, 1987. 23p. (Boletim científico, 11)

FOLLET, R.F. \& PETERSON, G.A. Surface soil nutrient distribution as affected by wheat-fallow tillage systems. Soil Science Society of America Journal, Madison, 52(1):141-147, 1988.

HARGROVE, W.L.; REID, J.T.; TOUCHTON, J.T. \& GALLAHER, RN. Influence of tillage practices on the fertility status of an acid soil double-cropped to wheat and soybeans. Agronomy Journal, Madison, 74(4):684-687, 1982.

LOPES, A.S. Solos sob "cerrado": características, propriedades e manejo. Piracicaba, Instituto da Potassa e Fosfato, 1983. 162p.

MAHLER, RJ.; BINGHAM, F.T.; PAGE, A.L \& RYAN, J.A. Cadmium-enriched sewage sludge application to acid and calcareous soils: effect on soil and nutrition of lettuce, corn, tomato, and swiss chard. Journal of Environmental Quality, Madison, 11(4):694-700, 1982.

PHILLIPS, S.H. \& YOUNG JUNIOR, H.M. No-tillage farming Milwaukee, Reimam Associates, 1973. 224p. 
SHEAR, G.M. \& MOSCHLER, W.W. Continuous corn by the no-tillage and conventional tillage methods. Agronomy Journal, Madison, 61(4):524-526, 1969.

SHUMAN, L.M. \& HARGROVE, W.L. Effect of tillage on the distribution of manganese, copper, iron, and zinc in soil fractions. Soil Science Society of America Journal, Madison, 49(5):1117-1121, 1985.
VALADARES, J.M.A. da S. O xinco em solos do Estado de São Paulo. Piracicaba, 1972. 72p. Tese (Doutorado em Agronomia) - ESALQ-USP, 1972.

VALADARES, J.M.S. da S. \& CAMARGO, O.A. de.Manganês em solos do Estado de São Paulo. Revista Brasileira de Ciência do Solo, Campinas, 7(2):123-130, 1983. 